\section{A Clinical Guide to Oral Medicine}

\section{2nd Edition}

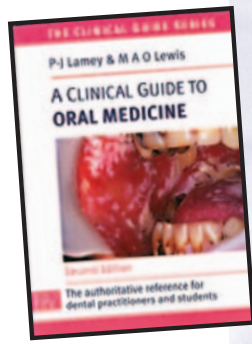

"This book is an excellent quick reference. It would be an asset for general dental practitioners who need to be comfortable recognising oral medicine conditions to enable them to treat or make appropriate referrals." - The GDP

\section{A Clinical Guide to} Periodontology

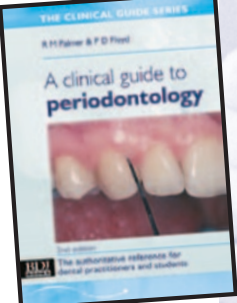

2nd Edition

R M Palmer and P D Floyd

A brand new 2nd edition of this popular book

- Completely revised and with new material and illustrations

- A chairside guide of clinical procedures for the general dental practitioner

A reminder and update for the qualified dentist and a summary of the basics for the student.

ON THE FIRST EDITION: "This book was inspiring, motivational and above all concise:" Dental $H$

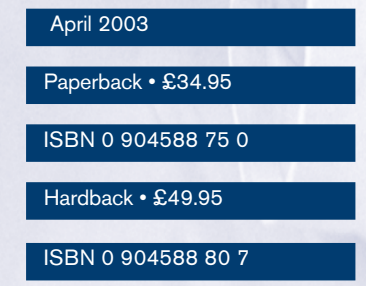

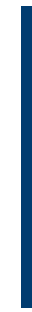

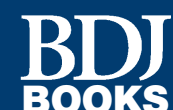

HOW TO ORDER: BDJ Books, BDA Shop British Dental Association 64 Wimpole Street London W1G 8YS, UK

\title{
No pain, no gain
}

Amputation, childbirth, torture, masochism, and sadism are to be explored in a major new exhibition about pain at London's Science Museum. The new exhibition, Pain: Passion, Compassion, Sensibility is a collaboration between The Wellcome Trust and the Science Museum and has been curated by the leading Spanish philosopher, Javier Moscoso.

Pain features over 170 objects and artworks - many rare and unseen - from the original collections of Sir Henry Wellcome, including the tooth of an Egyptian ghoul said to cure neck pain; a Victorian head perforator; Lord Lister's apparatus for application per rectum; 18th century German dental forceps; a carved wooden decapitated head; a 17th century German execution mask; torture equipment and a 16th century thumb screw.

Pain explores the changing cultural place of pain and the role of science in shaping our beliefs, from visual and verbal representations, medical attempts to deal with pain, examinations of modern and contemporary theories about the nature of pain and a look into our reactions to the pain of others.

Date: 13 February - 20 June 2004 Venue: 1st Floor, Science Museum, Exhibition Road, London, SW7 2DD Pre-Booking Line: 08708704868 Admission Free

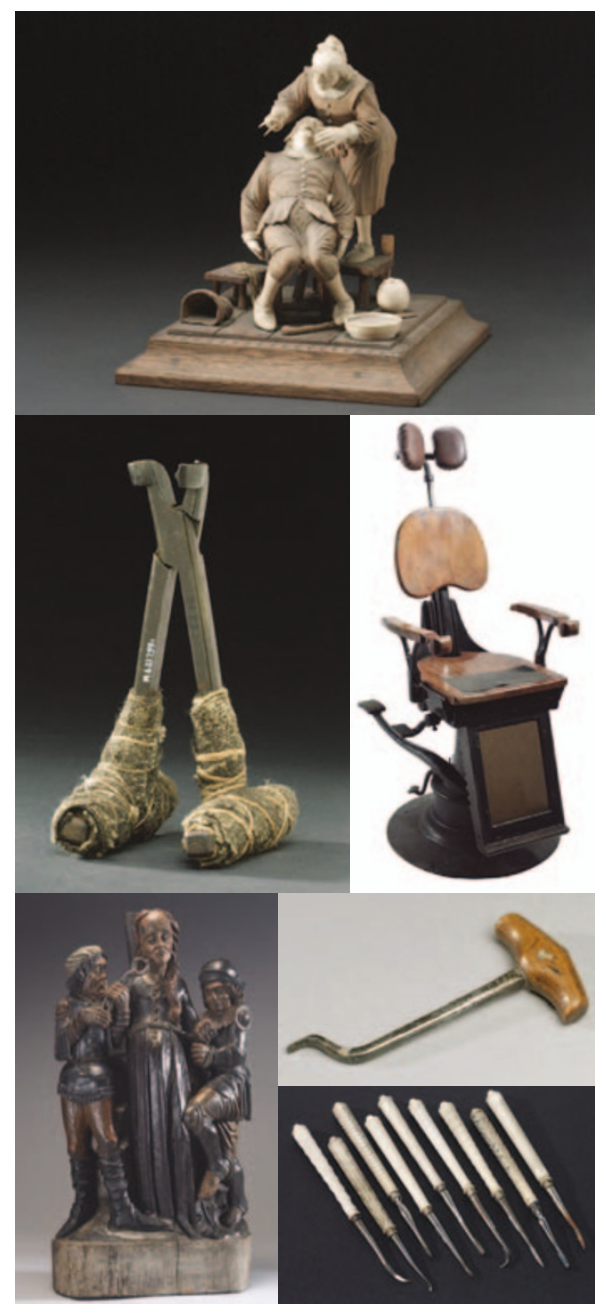

\section{Lifetime service award}

Mabel Slater, was recently awarded the Dr Leatherman Award for lifetime service to the dental hygienist profession. She has worked within the dental profession for almost 40 years, starting out as a dental nurse/practice manager in general practice in 1965. In 1968 she gained her dental nursing certificate and has gained further qualifications in dental hygiene, teaching and training.

She has been associate specialist lecturer at The Tameside College in Ashton-Under-Lyne, been principal at the dental hygienist training school of the Central Manchester Healthcare Trust and most recently has been the head of the Unit of Oral Health Science at the University of Manchester.

In addition to her career, Mabel had been extremely active on a variety of professional body committees and working groups. She has also held many positions within the BDHA, culminating in holding the presidency for 1998-2000.

She was recently elected onto the new council of the GDC, and has accepted the newly created post of Director of Professionals Complementary to Dentistry at Guy's, King's \& St Thomas' Trust in London.

She was presented with the award at the at the British Dental Hygienists' Association Scientific Conference and AGM in Harrogate. 
news in brief

Healihy snacks

The Departiment of Healith has

announced a scheme whereby

parents of toddlers will be able to

obtain free fruit and vegetables.
The move is an extension of the

existing scheme under which parents

eceive vouchers for free mill.

Parents on low incomes will be

eligible for the vouchers and the

Departiment of Health says it is

diming to improve nutrition in poore

amilies.

Health Secrefary John Reid said it

was not the government's role to

lecture families, but it wanted to

encourage people to eat more

healihily.

\section{Water Bill}

Communities across England and Wales are to be given the chance to choose to have fluoride added to their water supplies. In a vote on Clause 58 of the Water Bill in November MPs rejected an outright ban of fluoride schemes by a large margin and similarly voted against a move that would have put the power in the hands of local authorities rather than strategic health authorities. The Bill then moved smoothly to third reading, giving communities across England and Wales the chance to choose to have fluoride added to their water supplies.

\section{More change at Boots}

The 900 redundancies at Boots head office announced in January include staff who provide support services to the 56 Boots Dentalcare practices. At the time of going to press, it seemed likely that as many as 20 head office staff who work directly for the dental practices will opt for voluntary redundancy.

While this is few in relation to the overall job losses in Nottingham, where the head office team is being cut by 50 per cent, it is likely to have a considerable impact on the dental practices. One of the features of Boots practices which made them attractive to both staff and patients was the investment in standards and training for all the team.

Additionally, hygienists working for the high street chain are now being asked if they would like to work on a self-employed basis and the numbers of nurses across all the practices are being reduced

Chris Potts, the dentist who inspired Boots to move into high street dental provision, said the staff cuts were not just about saving money but reducing complexity at head office. There would in future be more emphasis on decision-making at practice level.

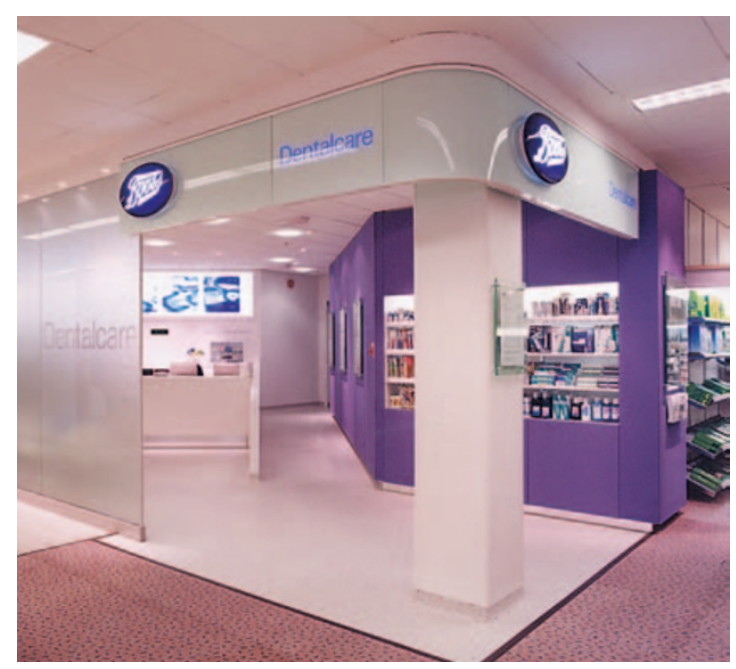

We value professionals complementary to dentistry and the proposals should not be seen as a Uturn. It's about doing things differently.'

Meanwhile, Sue Skinner, chairman of the British Dental Hygienists Association, said that while many hygienists were self-employed by choice, in some areas of the country the Inland Revenue was insisting that they should work on an employed basis.

She added: 'The BDHA wants whatever is in the best interest of members but we are not a trade union and therefore cannot negotiate on their behalf.'

\section{Dentistry 2005 update}

Well represented

PCD associations representing receptionists, dental nurses, dental therapists, practice managers,
hyalenists and technicians will be present at the BDA's British Dental Conference and Exhibition from 6-8 May 2004 at the Bournemouth International Centre, making this year's conference more relevant to PCD groups than ever before. The Conference and Exhibition coincides with the 2004 British Association of Dental Nurses Conference that will be held in Bournemouth on Saturday 8 May 2004
Last year the Secretary of State for Health published proposals to make fundamental changes to the way NHS dentistry is managed and provided from April 2005.

The proposals were included in the Health and Social Care Bill that was approved by Parliament and received Royal Assent in November.

Central to the changes is the devolution of responsibility for dental services from the Department of Health to Primary Care Trusts.

The consultation document Health and Social Care Act 2003 - Framework proposal for Primary Service in England from 2005 was circulated to all dentists in England in February.
The BDA have issued a questionnaire inviting comment on the document, which should be returned by 31 March 2004. The BDA will formally respond to the Department of Health by the end of April.

Rest of UK

The changes in the Health and Social Care Act apply to England and Wales. The Welsh Assembly Government has yet to clarify its intentions. In Scotland, the Scottish Executive has issued a consultation paper on exploring options for modernising dental services in Scotland. The situation in Northern Ireland is uncertain though policy-makers will be watching closely developments in England and Scotland. 


\section{Coke to drop advertising in schools}

Coca-Cola has announced that it is set to remove advertising for its soft drinks from the front of all its vending machines in British secondary schools between now and September.

The global soft drinks giant says its decision was based on its recognition of the conflict between vending machines in schools and classrooms as commercial-free areas.

Coca-Cola has 4,000 vending machines in about 1,500 secondary schools in England, Scotland and Wales and the scheme means pictures of cans of Coca-Cola or Fanta will be replaced with panels showing cartoon children playing with no branding at all.

The company also announced the machines would contain fewer choices of Coca-Cola products and more juice drinks and bottled water.

Commenting on the move, Cathy Stillman-Lowe, an independent oral health promotion expert, said 'Healthy eating (and drinking) in schools is a serious issue: there is a reciprocal relationship between education and health. Educational attainment plays a key role in determining health status and in breaking the cycle of health inequalities, and healthier children perform better academically. The whole school environment is as important as what is taught in the classroom, and easy access to sweetened or acidic drinks in schools could result in their frequent consumption, with negative impacts on oral and general health. The availability of bottled water in CocaCola vending machines is clearly a step in the right direction; even better, every school could make drinking water freely available in an attractive environment (not the toilets) to all pupils, irrespective of whether or not they can afford to buy drinks from the vending machine.'

\section{DLA says goodbye to chief executive}

The Dental Laboratories' Association (DLA) recently said goodbye to its chief executive Bill Courtney. He had been its chief executive since 1987, but had been actively

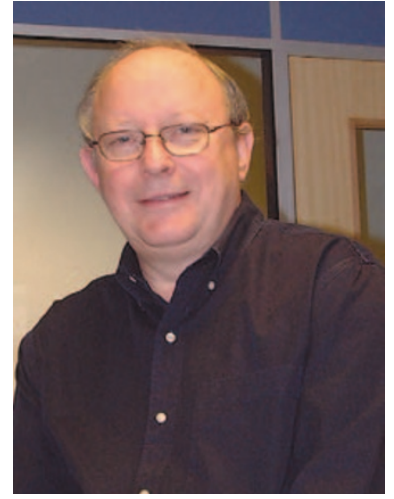
involved with the association since 1976.

He started his career as a self-employed technician in 1970 in London and by 1973 he was employing 14 people in a laboratory in High Wycombe The 1980s saw him selling his laboratory to a larger group, and setting up again in the south-west. He finally sold again to join the DLA full time in 1987.

During his time at the DLA, he had seen the association grow from less than 400 members to a body representing 50 per cent of the labs in the country and has seen a number of changes and developments in the industry.

Richard Daniels took over the role at the beginning of this year.

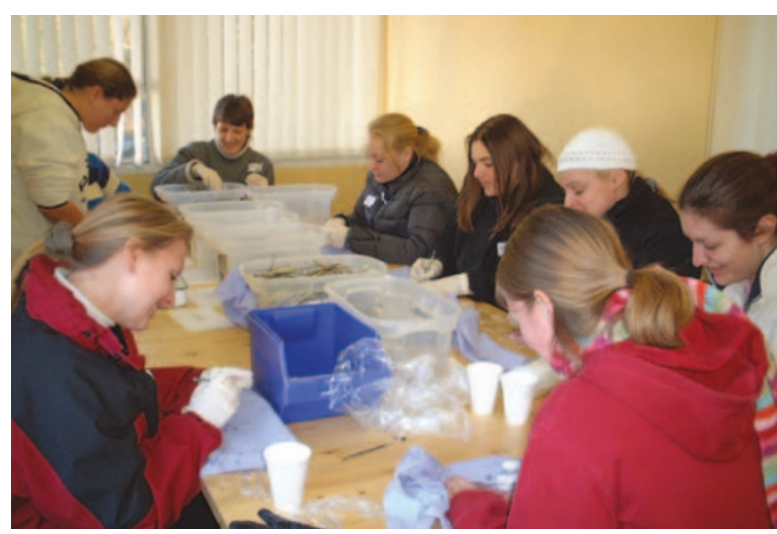

\section{Scaling new heights for Dentaid}

A group of 24 military student hygienists from the Dental Defence Agency (DDA) training establishment in Aldershot spent a day sorting thousands of dental instruments that were donated to charity Dentaid recently.

The student hygienists tackled the scaler mountain, which came from J\&S Davis' scaler 'Eco-Exchange' scheme. Dentaid now have a healthy stock of scalers ready to be sent to projects all over the developing world. The group's leader, senior aircraftswoman Emma Hornby, organised the visit following a Dentaid presentation to the DDA Dental Hygienists' Symposium in 2003.

There is a regular flow of all types of hand instruments into the Dentaid workshops. If you are dentally trained, and have some time to spare helping the charity in this way, please contact the Dental Executive, Jenny Wordley. Saturday visits can be arranged. Email: jenny@dentaid.org. Tel: 01794324249

\section{PCD roadshows to continue}

Following the success of events for PCDs in 2003, the General Dental Committee is continuing its programme of regional $P C D$ Roadshows across the UK in 2004.

Over 2,000 delegates have attended these free evening events so far. The events aim to give PCDs an opportunity to find out more about statutory registration and what it will involve. GDC members and staff, and representatives of $P C D$ professional associations, are also on hand to answer delegates' questions.

Most events take place around 6.00pm to 8.30pm, and a buffet is laid on for those attending. The full programme for events in 2004, together with details of how to book a place, are available on the GDC website http://www.gdcuk.org/pcds.html. Denta team members without internet access can call the GDC's PCD staff team on 02078873855.

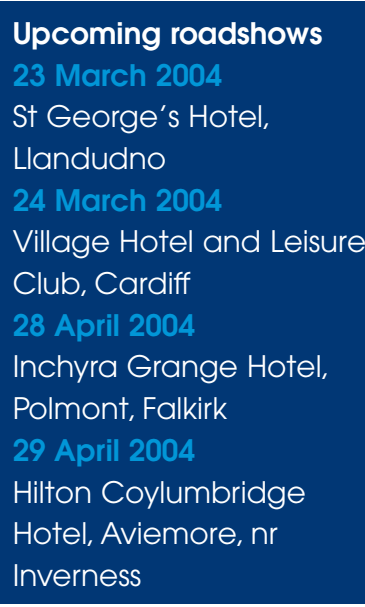




\section{Gateway agreement}

An umbrella organisation representing many of the technicians' associations has been set up to look at the issue of General Dental Council (GDC) registration. Organisations such as the Dental Technicians Association, the Dental Laboratories Association and the Clinical Dental Technicians Association are all members of the newly formed group.

The basis of the agreement was that the successful statutory registration of dental technicians with the GDC was of paramount importance and that all parties to this agreement would do all in their power to bring it about.

In addition the group agreed that all dental technicians with recognised qualifications as laid down by the GDC would be statutorily registered as dental technicians and that all unqualified persons working as dental technicians who met the conditions laid down by the GDC would be statutorily registered under the 'grandparenting' clause as registered dental technicians. This is on the condition that they had worked seven years (or part time equivalent) in the past 10 years and were able to manufacture a range of dental appliances within a discipline from impression to finish.

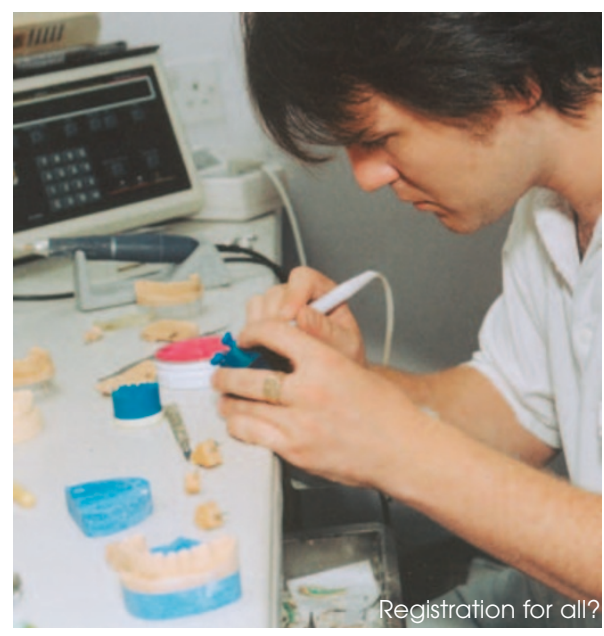

All other personnel employed in the fabrication of dental appliances must be on a recognised course of instruction, leading to a registerable qualification in dental technology. This can be full or part time but must take not longer than seven years to complete and all students will be enrolled and the roll will be maintained by the DTA. The group also stated that the signatories to this agreement were prepared to work closely with the GDC in supporting and implementing this.

\section{Tooth fairies raise cash for charity}

\author{
Integrated Dental \\ Holdings \\ Tannochside \\ Dental Centre \\ raised just over \\ £145 for Children in \\ Need by dressing \\ up as tooth fairies, \\ complete with \\ wings and wands \\ and organising \\ competitions for \\ the younger \\ patients. The team \\ also enlisted the \\ support of the
}

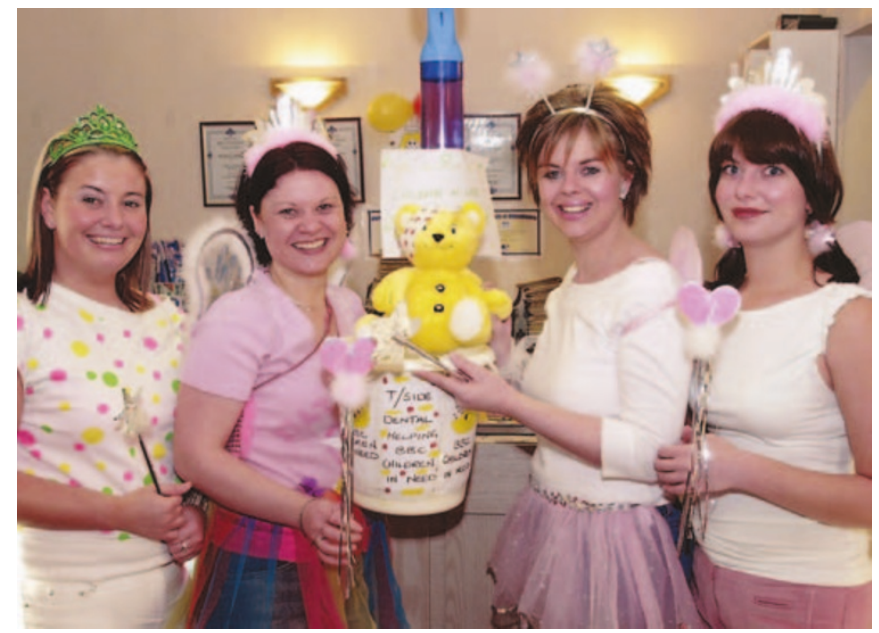

local Safeways store, who donated apples and oranges for patients. (Pictured left to right: Stacey Allen, Carol Dyer, Becky Brown and Michelle McParland). Practice manager Sandra Gemmell commented: 'We were delighted by the support we received from our dentists and patients. The day was great fun.'

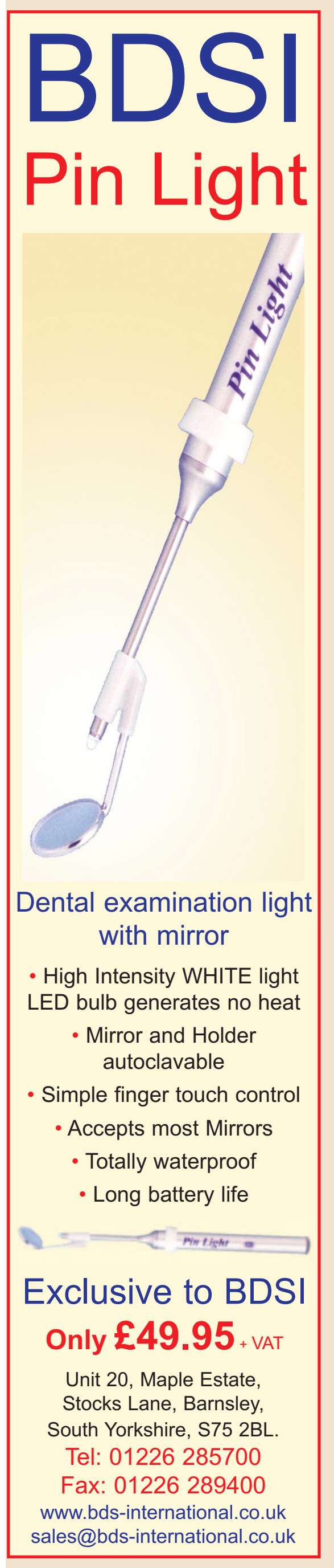

